\title{
The benthic macro-invertebrate diversity in relation to water quality of a stream habitat at Dediyagala, Sri Lanka
}

\author{
H.M.T.C. MADHUSHANKHA, H.B. ASANTHI* and R.A. \\ MAITHREEPALA
}

Department of Limnology, Faculty of Fisheries and Marine Sciences \& Technology, University of Ruhuna, Matara, Sri Lanka

*Corresponding author (asanthi@fish.ruh.ac.lk)

\begin{abstract}
The streams collect sediment and other fine and particulate material from their watersheds and transport them downstream as fluvial material. Macro-benthos is the most important secondary producers in stream ecosystem and their diversity explains the water quality of a stream to a greater extent. The present study determines the water quality and macro-benthos diversity at five sites of the $180 \mathrm{~m}$ stream stretch at Dediyagala for a period of three months from February to April in 2012. Random samples were collected using a Surber sampler for benthos, and a Ruttner sampler for water samples.

Water discharge was significantly different from headwater $\left(0.0198 \mathrm{~m}^{3} \mathrm{~s}^{-1}\right)$ to downstream $\left(0.0456 \mathrm{~m}^{3} \mathrm{~s}^{-1}\right)$. Bottom substrate was non uniform according to Uniformity Coefficient analysis except at two sampling sites of cascade and riffle habitats. There was no significant site specific or time specific variations in water temperature, $\mathrm{pH}$, biochemical oxygen demand $\left(\mathrm{BOD}_{3}\right)$, total suspended solids (TSS), total dissolved solids (TDS), and orthophosphate concentration. Nitrate concentration, dissolved oxygen (DO) and organic matter content of lithophytes varied significantly among the sampling sites $(\mathrm{P}<0.05)$. Principal Component Analysis (PCA) showed that TDS and DO were the most important parameters for explaining the water quality of the stream stretch studied whereas $\mathrm{BOD}_{3}$ was important only for the downstream site.

The most abundant families of benthic organisms in the stream were Hydropsychidae, Helicopsychidae, Leptophelibiidae and Psephenidae which belonged to the orders of Trichoptera, Ephemeroptera, and Coleoptera. A Significant positive correlation was observed between DO and Shannon-Wiener diversity index $\left(\mathrm{R}^{2}=0.815, \mathrm{P}<0.05\right)$. Family Biotic Index $(\mathrm{FBI})$ ranged between 2.63 and 3.16 indicating that water quality was suitable for healthy growth of macro-invertebrates in the stream.
\end{abstract}

Keywords: FBI index, Lithophytes, Uniformity Coefficient, Macro-benthos, Diversity 


\section{Introduction}

Headwater streams are critical sites for organic matter processing and nutrient cycling and they are vital for maintaining the health of whole river network (Bengtsson 1998). According to Clarke et al. (2008), the headwater streams are named as nutrient poor, less productive areas and macro-benthos in these areas provides a greater contribution to the secondary productivity in the streams.

River continuum concept (RCC) is one of the conceptual models to describe river ecosystems and integrity of abiotic and biotic environment (Vannote et al. 1980). This concept is based on streams that originate in forested regions and integrates the geomorphological features of streams with the composition and function of the biological communities (Leprieur et al. 2009).Stream discharge is also an important character of stream ecology because it interacts with the gradient and substrate to determine the types of habitats present, the shape of the channel and the composition of the stream bottom (Dai and Trenberth 2002).

Benthic macro-invertebrate species are differentially sensitive to many biotic and abiotic factors in their environment (Mandaville 2002). Relative abundance and diversity of their community have commonly been used as an indicator of the condition of an aquatic system (Mandaville 2002; Azrina et al. 2005). Therefore, freshwater benthic macro-invertebrates can be commonly used as ecological indicators of aquatic ecosystems. Their populations depend on the condition of the environment such as water quality, organic matter content, soil texture, sediment particles and the ability to construct permanent burrows in the substratum (Dahanayaka and Wijeyaratne 2006). Biological monitoring or its chemical contents, is important in determining the health of an aquatic ecosystem. Physicochemical monitoring of a water body is known to be insufficient to fully characterize its status or reliably detect adverse impacts (Mandaville 2002).

The technique of using macro-benthic invertebrates as bio-indicators is a cost effective method widely used in the Northern American and European ecoregions (Azrina et al. 2005) but not a popular method or an option in the Asian region in river classification. Due to the lack of expertise and information on benthic macro-invertebrate populations, they have not properly used as bioindicators especially in pollution studies in Sri Lanka.

Many studies have reported that anthropogenic activity such as agriculture, recreation, silviculture, land clearing, urban development, and river impoundment resulting organic and metal contamination affect the abundance and distribution of freshwater macro-benthos (Wahizatul et al. 2011). As such, this research was an attempt to determine the use of aquatic macro-benthos in assessing and classifying the health status of selected freshwater stream, through analyzing the macro-benthos diversity, surface water quality, and substrate characteristics in a selected part of a stream. 


\section{Materials and Methods}

\section{Site description}

Kanneliya (K), Dediyagala (D) and Nakiyadeniya (N) are contiguous reserves forming a compact forest unit with a total extent of 121,964 ha located in southwest of Sri Lanka. This (KDN) biosphere reserve covers lowland and tropical montne forests, and lies between two rivers (Jayasuriya and Abayawardana 2008). KDN Complex is ranked as the most important natural forest in the Southern Province for the protection of headwaters of river systems including 111 streams (Jayasuriya and Abayawardana 2008).

One of the streams which begins from the Dediyagala forest and connects to the Nilwala River at the low land area was selected as the study area. Five sampling sites (site 1- site 5) within $180 \mathrm{~m}$ stream stretch were used for collecting water and biological samples on monthly basis (Figure 1). These five sampling sites were selected according to the flow characteristics. Site 1 was near to a cascade, sites 2, 3, 4 were riffles and site 5 was a pool habitat. Water quality parameters and biological parameters were measured during the study period from February to April, 2012 on monthly basis.

\section{Determination of physical characteristics of the stream}

The mid-section method (USEPA, 2012) was applied to compute stream discharge by using a digital current meter (Kenek/VP/1000, Japan). Particle size distribution of sediments was determined using mechanical sieve sets (sample divider) (Serial no: 12101706201 and model: AS 200 basic, Germany) based on the remaining mass in each sieve and the proportions retained in each sieve was used to determine \% stream substrate composition. Accordingly, collected soil was separated using seven different sizes of sieves to obtain a breakdown of particle size and the particle size distribution curves were drawn for each site. The particle size distribution curve is a semi-logarithmic graph and it was used to determine useful soil parameters $\mathrm{D}_{30}, \mathrm{D}_{10}$ and $\mathrm{D}_{60}$ in each site (Sivakugan 2000). $\mathrm{D}_{30}$ is a size such that $30 \%$ of the soil particles are smaller than his size and similarly $\mathrm{D}_{10}$ and $\mathrm{D}_{60}$ were determined. $\mathrm{D}_{10}$ is called the effective grain size, which gives a good indication of the permeability characteristics of a coarse grained soil. Then the coefficient of uniformity $\left(\mathrm{C}_{\mathrm{u}}\right)$ and coefficient of curvature $\left(\mathrm{C}_{\mathrm{c}}\right)$ were calculated using the following equations (Sivakugan 2000; Wade 2007;). 


$$
\begin{aligned}
& C_{u}=\frac{D_{10} / D_{60}}{C_{c}}=\frac{D_{30}{ }^{2}}{\left(D_{10} \times D_{60}\right)}
\end{aligned}
$$

Where;

$\mathrm{D}_{10}$ - Particle diameter that is $10 \%$ of finer [effective grain size]

$\mathrm{D}_{60}$ - Particle diameter that is $60 \%$ of finer

$\mathrm{D}_{30}$-Particle diameter that is $30 \%$ of finer

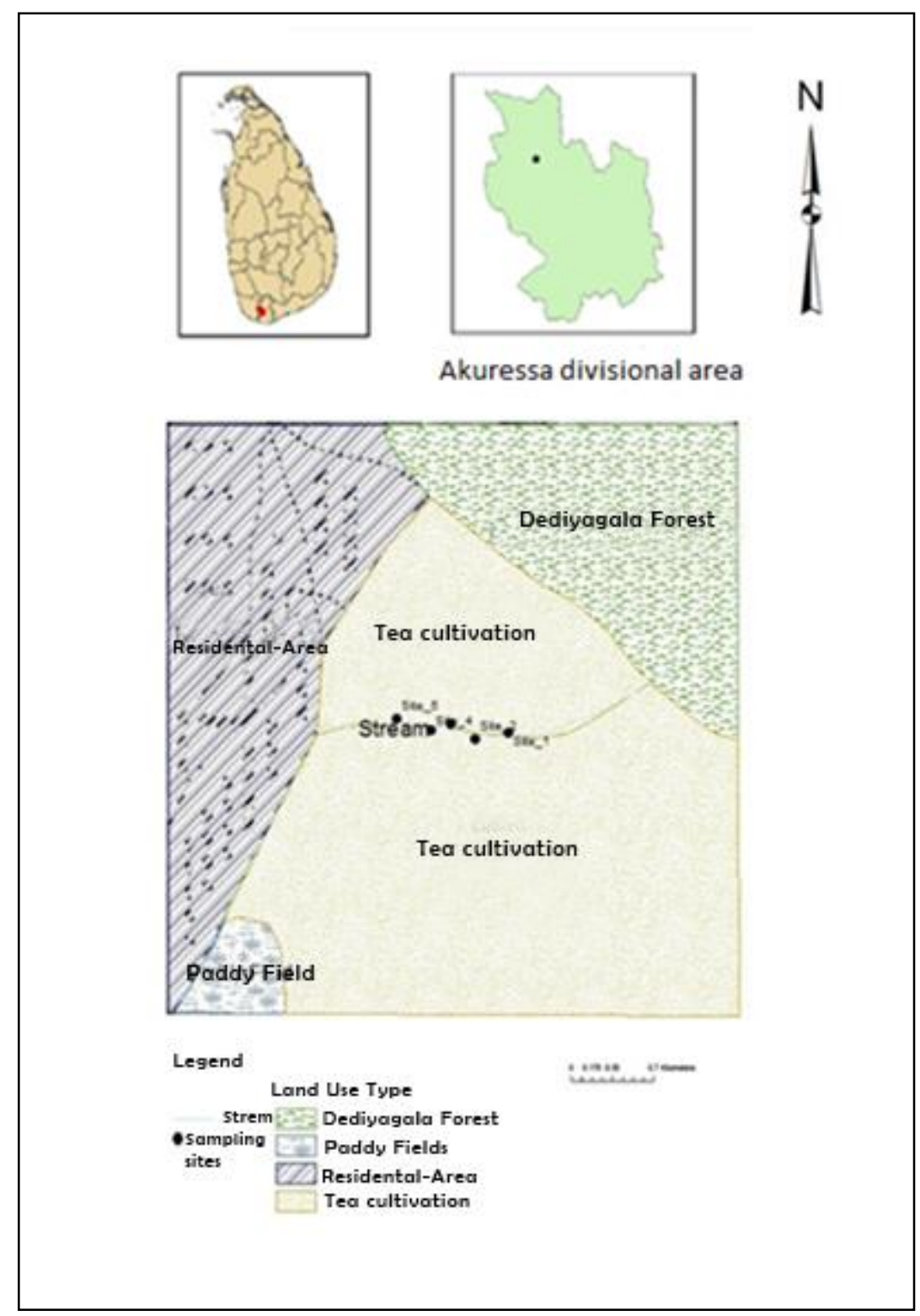

Figure 1. Locations of study sites. 


\section{Determination of chemical parameters}

Water samples with three replicates were collected pre-washed bottles at each sampling site using a Ruttner sampler and kept in ice until arrival to the laboratory. The samples were analyzed for total suspended solid (TSS), total dissolved solid (TDS).Orthophosphate and Nitrate-N concentrations were measured by colorimetric method using UV spectrophotometer. Dissolved oxygen (DO) concentration and Biochemical oxygen demand $\left(\mathrm{BOD}_{3}\right)$ were determined using the Winkler method (APHA 1985).

\section{Collection and identification of benthic macro-invertebrates}

Random sampling technique was employed to collect benthos using a Surber sampler. Macro-invertebrates were separated from the sediment and preserved in $70 \%$ alcohol until further analysis. Several identification keys such as Bouchard (2004), Hartmann (2006), Dailey (2006), River Watch Network 1992), and Fernando and Weerawardhena (2002) were used to identify the collected benthic organisms at least up to their family level.

Shannon-Wiener diversity index $(\mathrm{H})$ was calculated using the following equation.

$$
\mathrm{H}=-\sum\left(\mathrm{p}_{\mathrm{i}}\right)\left(\ln \mathrm{p}_{\mathrm{i}}\right)
$$

Where $\mathrm{p}_{\mathrm{i}}$ is the proportion of individuals in the $\mathrm{i}^{\text {th }}$ taxon of the community.

EPT index (Ephemeroptera, Plecoptera, and Trichoptera index) displays the taxa richness within the insect groups which are considered to be sensitive to pollution. The EPT index is equal to the total number of families represented within these three orders in the sample of each site (Mandaville 2002).

Family Biotic Index (FBI) provides a single tolerance value which is the average of the tolerance values of all species within the benthic arthropod (Mandaville 2002).

$$
\mathrm{FBI}=\sum \frac{x_{i} t_{i}}{\mathrm{n}}
$$

where $x_{i}$ is the number of individuals in the $\mathrm{i}^{\text {th }}$ taxon, $\mathrm{t}_{i}$ is the tolerance value of the $\mathrm{i}^{\text {th }}$ taxon and $\mathrm{n}$ is the total number of organisms in the collected benthos sample of each site.

\section{Statistical analysis}

One-way ANOVA was used to analyze the spatiotemporal variation of physicochemical parameters in the stream. The principal component analysis (PCA) was employed as a method of data reduction to select the most suitable parameters for explaining the biological variation at the sampling sites based on the covariance or correlation matrix. 


\section{Results}

\section{Physical characteristics of the stream}

The depth profiles of each site shown in Figure 2 explain the depth variation between the stream banks at each site. Maximum width $(7 \mathrm{~m})$ was recorded at the cascade habitat (site 1) and minimum width $(3.8 \mathrm{~m})$ was recorded at a riffle habitat of site 3. Average maximum depth $(0.57 \mathrm{~m})$ was recorded from site 1 and the minimum average depth $(0.29 \mathrm{~m})$ was at the site 2 .

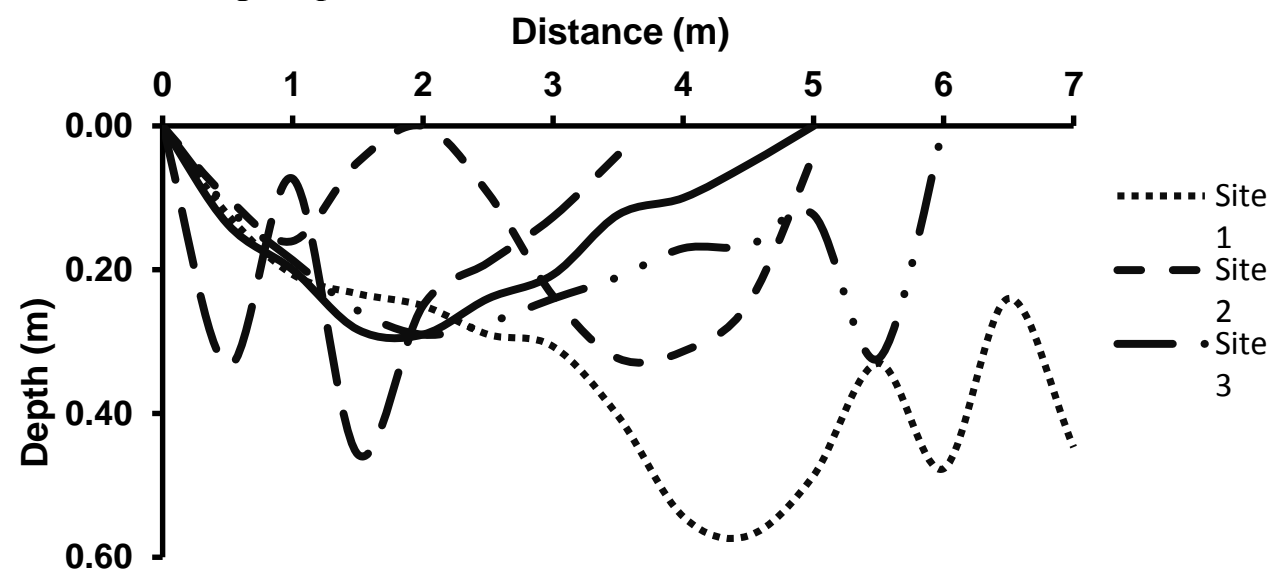

Figure 2. Depth profile at the sampling sites.

According to the Table 1 there was a significant difference of stream discharge among the sampling sites $(\mathrm{p}<0.05)$. The highest discharge was observed at the site 4 and the lowest discharge was observed at the site 3 of riffle habitats. The bottom substrate composed with several particles, those have been categorized according to the grain size. Gravel is the larger particles (particle size $>2 \mathrm{~mm}$ ), sand is medium size (particle size $2>0.06 \mathrm{~mm}$ ) and silt and clay can be categorized as one category (particle size $0.06>0.002 \mathrm{~mm}$ ). The Figure 3 describes the distribution of gravel, sand and silt and clay in the stream habitat during the study period.

Table 1. Water discharge of the stream at the sampling sites.

\begin{tabular}{cc}
\hline $\begin{array}{l}\text { Sampling } \\
\text { Site }\end{array}$ & $\begin{array}{l}\text { Stream } \\
\left(\mathrm{m}^{3} \mathrm{~S}^{-1}\right)(\text { mean } \pm \mathrm{SD})\end{array}$ \\
\hline 1 & $0.042 \pm 0.004$ \\
2 & $0.037 \pm 0.003$ \\
3 & $0.019 \pm 0.004$ \\
4 & $0.045 \pm 0.001$ \\
5 & $0.035 \pm 0.004$ \\
\hline
\end{tabular}


Relatively high percentage of sand can be observed at the cascade habitat of the stream (site 1) and at the pool habitat (site 5). However, gravel was predominant in all other three sampling sites and percentage of silt and clay composition gradually increases from site 1 to site 5 (Figure 3 ).

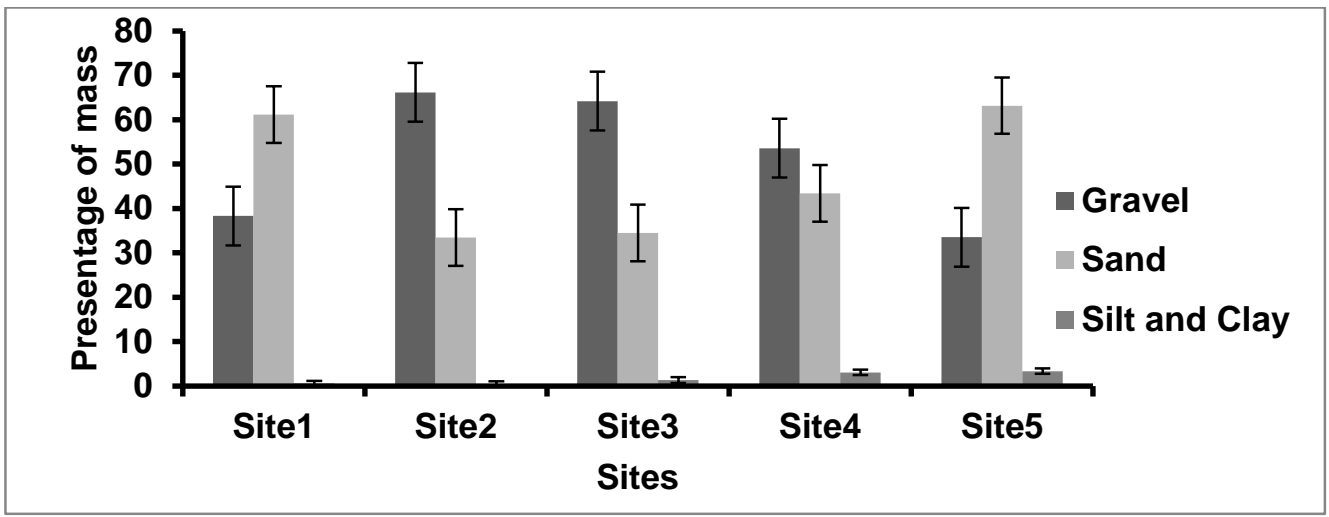

Figure 3. Percentage composition of substrate particles at the sampling sites.

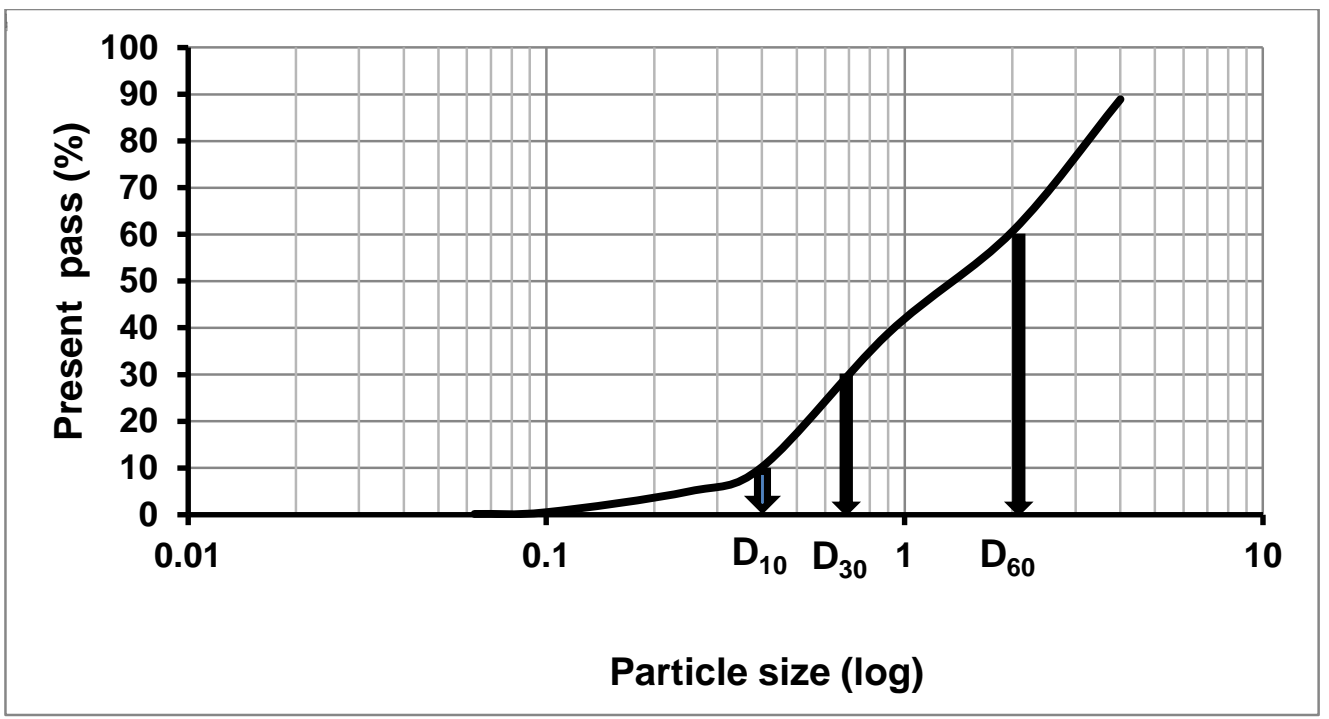

Figure 4. Semi-log curve for site 1. 
Coefficient of uniformity $\left(\mathrm{C}_{\mathrm{u}}\right)$ and coefficient of gradation $\left(\mathrm{C}_{\mathrm{c}}\right)$ are shown in Table 2. $\mathrm{C}_{\mathrm{u}}$ of the site 1 (cascade) and site 2 (riffle) were equal or lower than 5 and it explains uniform substrate structure. Meanwhile, $\mathrm{C}_{\mathrm{u}}$ of other three sites was greater than 5 refer as non uniform substrate at the downstream sites of riffle and pool habitats (site 3 , site 4 and site 5). Even though sediment composition was non uniform at the downstream sites the $\mathrm{C}_{\mathrm{c}}$ values at all five sites were lower than five explains that the presence of well graded soil type at each sampling site. The Figure 4 shows the semi-log curve for site 1 as an example and it indicates the $\mathrm{D}_{10}, \mathrm{D}_{30}$ and $\mathrm{D}_{60}$ values of $0.40,0.71$ and 0.80 respectively those were used for the calculation of $\mathrm{C}_{\mathrm{u}}$ and $\mathrm{C}_{\mathrm{c}}$.

Table 2. Coefficient of gradation $\left(\mathrm{C}_{\mathrm{c}}\right)$ and Uniformity coefficient $\left(\mathrm{C}_{\mathrm{u}}\right)$ at the sampling sites.

\begin{tabular}{llllll}
\hline & Site 1 & Site 2 & Site 3 & Site 4 & Site 5 \\
\hline $\mathrm{C}_{\mathrm{u}}$ & 5.00 & 3.67 & 5.82 & 6.83 & 6.40 \\
$\mathrm{C}_{\mathrm{c}}$ & 0.84 & 3.43 & 1.07 & 1.97 & 2.45 \\
\hline
\end{tabular}

\section{Water quality parameters}

The water-quality data of stream habitats are summarized as the mean \pm SD and are given in Table 3.Water temperature, $\mathrm{pH}$, biochemical oxygen demand $\left(\mathrm{BOD}_{3}\right)$, total suspended solid (TSS), total dissolved solid (TDS), and orthophosphate concentration did not vary significantly among the sampling sites and among the sampling days. However, dissolved oxygen (DO), nitrate- $\mathrm{N}$ concentration and organic matter content of lithophytes varied significantly among the sampling sites $(\mathrm{p}<0.05)$.

According to the results of PCA, the first component which represents $>50 \%$ of the total variation on the rotated component matrix explained the importance of physicochemical characteristics at all the sites. According to the coefficient values in Table 4, DO was an important parameter for explaining the biological variation at the all sampling sites. Similarly, TDS was an important factor at all the sites except the site 5 . 
Table 3. Water quality parameters at the sampling sites (mean $\pm \mathrm{SD}$ ).

\begin{tabular}{llllllllll}
\hline Site & $\begin{array}{l}\text { Temperature } \\
\left({ }^{\circ} \mathrm{C}\right)\end{array}$ & $\mathrm{pH}$ & $\begin{array}{l}\mathrm{DO} \\
(\mathrm{ppm})\end{array}$ & $\begin{array}{l}\mathrm{BOD} \\
(\mathrm{ppm})\end{array}$ & $\begin{array}{l}\text { TSS } \\
(\mathrm{mg} / \mathrm{L})\end{array}$ & $\begin{array}{l}\text { TDS } \\
(\mathrm{mg} / \mathrm{L})\end{array}$ & $\begin{array}{l}\text { Orthophosphate } \\
\text { Concentration } \\
(\mathrm{ppm})\end{array}$ & $\begin{array}{l}\text { Nitrate-N } \\
\text { concentration } \\
(\mathrm{ppm})\end{array}$ & $\begin{array}{l}\text { Percentage } \\
\text { organic } \\
\text { matter }(\%)\end{array}$ \\
\hline 1 & $25.3 \pm 0.7$ & $6.6 \pm 0.0$ & $10.5 \pm 0.5$ & $1.9 \pm 0.1$ & $6.8 \pm 1.5$ & $88.7 \pm 8.5$ & $0.02 \pm 0.00$ & $0.12 \pm 0.02$ & $0.93 \pm 0.02$ \\
2 & $24.9 \pm 0.5$ & $6.5 \pm 0.1$ & $10.1 \pm 0.7$ & $1.6 \pm 0.2$ & $3.3 \pm 1.3$ & $79.0 \pm 7.8$ & $0.01 \pm 0.00$ & $0.15 \pm 0.03$ & $0.89 \pm 0.01$ \\
3 & $24.8 \pm 0.3$ & $6.4 \pm 0.1$ & $11.3 \pm 0.2$ & $1.6 \pm 0.3$ & $2.6 \pm 1.1$ & $79.0 \pm 4.6$ & $0.02 \pm 0.00$ & $0.22 \pm 0.03$ & $1.16 \pm 0.03$ \\
4 & $25.0 \pm 0.7$ & $6.4 \pm 0.1$ & $9.6 \pm 0.2$ & $2.0 \pm 0.5$ & $4.9 \pm 1.5$ & $85.0 \pm 2.6$ & $0.01 \pm 0.00$ & $0.34 \pm 0.05$ & $0.58 \pm 0.02$ \\
5 & $24.5 \pm 0.3$ & $6.5 \pm 0.1$ & $10.6 \pm 0.6$ & $1.7 \pm 0.4$ & $3.8 \pm 2.5$ & $63.0 \pm 6.2$ & $0.02 \pm 0.00$ & $0.21 \pm 0.03$ & $0.91 \pm 0.02$ \\
\hline
\end{tabular}


Table 4. Coefficient values on component 1 in rotated component matrixes for different physicochemical characteristics at the sites.

\begin{tabular}{lccccc}
\hline Parameter & \multicolumn{5}{c}{ Sites } \\
\cline { 2 - 6 } & 1 & 2 & 3 & 4 & 5 \\
\hline DO & 0.998 & 0.764 & 0.787 & -0.982 & 0.787 \\
TDS & 0.991 & 0.987 & 0.98 & -0.796 & -0.052 \\
Organic & 0.983 & 0.275 & -1 & -0.392 & -0.945 \\
$\begin{array}{l}\text { matter content } \\
\text { of lithophytes }\end{array}$ & & & & & \\
$\begin{array}{l}\text { Stream } \\
\text { discharge }\end{array}$ & -0.944 & -0.928 & -0.253 & -0.253 & 0.875 \\
\hline
\end{tabular}

\section{Biological parameters}

Aquatic insects collected from stream habitats during the study period were represented by 17 families from 6 orders. Ephemeroptera, Plecoptera, Trichoptera and Coleoptera were the most abundant orders of the stream habitats. ShannonWiener diversity index, Ephemeroptera, Plecoptera and Trichoptera index (EPT) and Family biotic index (FBI) values are given in Table 5. The EPT value varied between 2 at the site 5 of pool habitat and 8 at the site 3 of riffle habitat of the stream. Meanwhile, the FBI value varied between 2.53 at the site 2 of riffle and 3.28 at the site 5 of pool habitat. However, there was no significant site-specific difference of any of above said index values. The identified families in each order with their total abundance in the study period are given in the Table 6 . The highest total abundance $\left(432 / \mathrm{m}^{2}\right)$ was observed for family Leptophlebiidae in order of Ephemeroptera. Shannon-Wiener diversity index $(\mathrm{H})$ shows a significant positive correlation with dissolved oxygen (DO) concentration in the stream (Figure 5) and with the percentage of organic matter content in lithophytes (Figure 6).

Table 5. Biological parameters. FBI - Family Biotic Index; EPT Index Ephemeroptera, Plecoptera and Trichoptera index

\begin{tabular}{cccc}
\hline $\begin{array}{c}\text { Sampling } \\
\text { Site }\end{array}$ & $\begin{array}{c}\text { Shannon-Wiener } \\
\text { diversity index }(\mathrm{H})\end{array}$ & FBI & EPT Index \\
\hline 1 & $1.927 \pm 0.19$ & $2.93 \pm 0.05$ & $4 \pm 1.00$ \\
2 & $1.692 \pm 0.25$ & $2.63 \pm 0.10$ & $4 \pm 1.73$ \\
3 & $2.256 \pm 0.13$ & $2.91 \pm 0.07$ & $6 \pm 2.00$ \\
4 & $1.613 \pm 0.91$ & $2.99 \pm 0.08$ & $5 \pm 1.73$ \\
5 & $1.730 \pm 0.26$ & $3.16 \pm 0.12$ & $4 \pm 2.00$ \\
\hline
\end{tabular}


Table 6. Aquatic insect families and total abundance at five sites during the study period.

\begin{tabular}{lll}
\hline Taxonomic order & Family & Total abundance $\left(\mathrm{nos} \mathrm{m}^{-2}\right)$ \\
\hline Odonata & Euphaeidae & 52 \\
& Gomphidae & 16 \\
Ephemeroptera & Calopterygidae & $<4$ \\
& Leptophlebiidae & 432 \\
& Baetidae & 20 \\
& Ephemeridae & 56 \\
Diptera & Hepatageniidae & 84 \\
& Athericidae & 4 \\
& Psychodidae & 4 \\
Coleoptera & Simulidae & $<4$ \\
Trichoptera & Chironomidae & 12 \\
& Psephenidae & 300 \\
& Elmidae & 4 \\
Plecoptera & Helicopsychidae & 192 \\
& Odontoceridae & $<4$ \\
& Hydropsychidae & 220 \\
& Perlidae & 8 \\
\hline
\end{tabular}

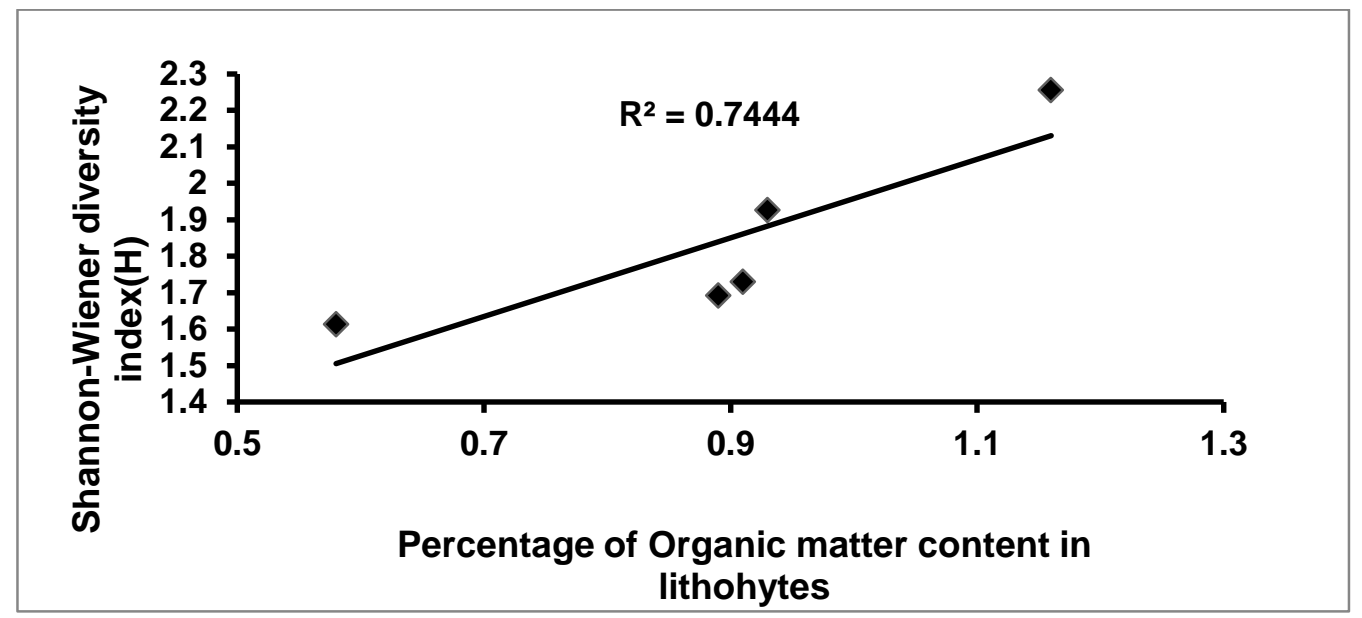

Figure 5. Relationship between $\%$ of organic matter in lithophytes and Shannon index. 


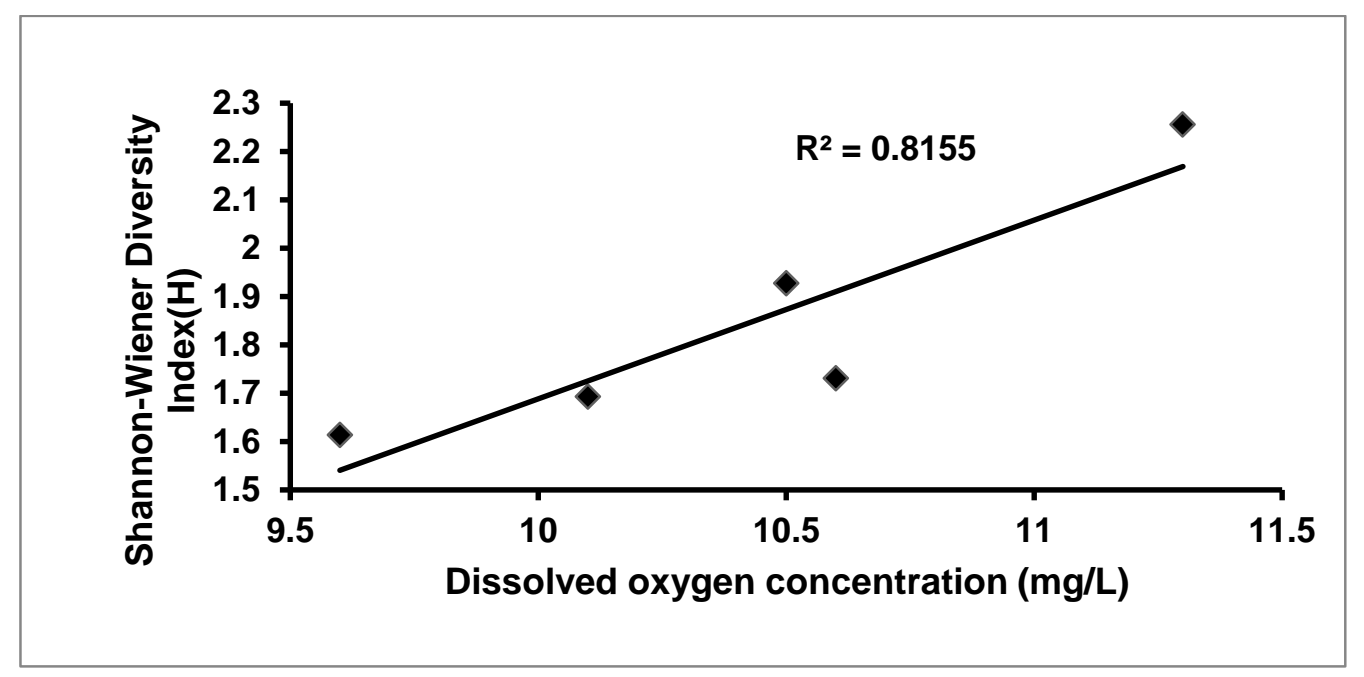

Figure 6. Relationship between Dissolved oxygen and Shannon Wiener index.

\section{Discussion}

The upstream area of the stream contains much more cobbles and pebbles than silt and clay and the substrate characteristics are often sensitive indicators of the effect of human activities on the streams (Toriman et al. 2009). Increase of silt and clay in the stream as found in the present study can be due to land use activities in the area including deforestation for tea cultivation. Urban and agricultural land uses and deforestation are reported to often increase the sediment and nutrient load of streams and it may reduce the habitat space and its availability for benthic fish and macro invertebrates (Houser et al. 2006).

Accumulation of dead leaves (allochthonous materials) was a distinct feature of pool habitats in the stream and it could be a reason for relatively low $\mathrm{pH}$ at these sites due to release of acidic substances (humic acid) from these materials (Young et al. 2009). The significant positive correlation that was observed between benthic organisms diversity and DO concentration in water would be due to the reason that as mentioned by Silva (2009), DO concentrations in water can vary dramatically as a result of various physical, chemical, and biological processes. Similarly, a significant positive correlation between organic matter content of lithophytes and diversity benthic organisms of was observed. Relatively higher organic matter content in lithophytes was observed at the riffle habitat (site 3) with the presence of more gravels and large boulders. According to Munari and Mistri (2007) biogeochemical processes in the sediments and sediment stability and presence of meiofaunal and nekton communities are important for diversity variation of macro-benthos in streams. In the present study the significant difference of benthos diversity among the sampling sites explains that the variation of substrate characteristics and water quality in the stream. 
H.M.T.C. Madhushankha et al./Sri Lanka J. Aquat. Sci. 19 (2014): 15-29

Table 7. Values of family biotic index and relevant water quality (Mandaville 2002).

\begin{tabular}{lll}
\hline $\begin{array}{l}\text { Family biotic } \\
\text { index }\end{array}$ & $\begin{array}{l}\text { Water } \\
\text { quality }\end{array}$ & Degree of organic pollution \\
\hline $0.00-3.75$ & Excellent & Organic pollution unlikely \\
$3.76-4.25$ & Very good & Possible slight organic pollution \\
$4.26-5.00$ & Good & Some organic pollution probable \\
$5.01-5.75$ & Fair & Fairly substantial pollution likely \\
$5.76-6.50$ & Fairly poor & Substantial pollution likely \\
$6.51-7.2$ & Poor & Very substantial pollution likely \\
$7.26-10.0$ & Very poor & Severe organic pollution likely \\
\hline
\end{tabular}

The most abundant group of benthic macro-invertebrates in streams is generally aquatic insects, which account for $\sim 70 \%$ of known species of major groups of aquatic macro-invertebrates (Mandaville 2002). Among the aquatic insects the taxonomic orders of Ephemeroptera, Plecoptera, Tricoptera, Coleoptera and Odonata were found to be highly abundant during the present study. Leprieur et al. (2009) have documented that most of the agricultural sites show lower EPTC (Ephemeroptera, Plecoptera, Tricoptera, Coleoptera) taxa richness and diversity than the forest sites. The PCA has shown that DO was the most important parameters of each site for explaining the macro-benthos diversity and abundance in the stream. Abundance of the families of benthic macro-invertebrates can be used to assess the water quality according to their tolerance value and the FB index which indicates excellent water quality of the Dediyagala stream (Table 7; Mandaville 2002).The taxonomic orders of Ephemeroptera, Plecoptera, Trichoptera and Coleoptera can be used to assess response of anthropogenic disturbances in rivers (Leprieur et al. 2009). Therefore, the EPT index values at the sites of the stream describe the water quality as slightly impact $(6-10)$ or moderately impact $(2-5)$ according to the classification given by Mandaville (2002). According to the EPT and FBI values for the stream the water quality is suitable for the healthy life of macro-invertebrates in the period of study.

\section{References}

American Public Health Association (APHA) 1985.

Standard Methods for the Examination of Water and Wastewater. 19th Edition.Washington D.C.

Azrina, M.Z., C.K. Yap, A.R. Ismail, A. Ismail and S.G. Tan 2005.

Anthropogenic impacts on the distribution and biodiversity of benthic macroinvertebrates and water quality of the Langat River, Peninsular Malaysia. Ecotoxicology and Environmental Safety 64 (3): 337-347. 
Bengtsson, J. 1998.

Which species? What kind of diversity? Which ecosystem function? Some problems in studies of relations between biodiversity and ecosystem function. Journal of Applied Soil Ecology 10: 191-199.

Bouchard, R.W., Jr. 2004.

Guide to Aquatic Macroinvertebrates of the Upper Midwest. Water Resources Centre, University of Minnesota, St. Paul, MN. 208 p.

Clarke, A., R.M. Nally,N. Bondand P.S. Lake 2008.

Macro invertebrate diversity in headwater streams: A review. Freshwater Biology 53: 1707-1721.

Dahanayaka, D.D.G.L. and M.J.S. Wijeyaratne 2006.

Diversity of macrobenthic community in the Negambo estuary, Sri Lanka with reference to environmental conditions. Sri Lanka Journal of Aquatic Sciences 11: 43-61.

Dai, A. and K.E. Trenberth 2002.

Estimating of fresh water discharge from continents: Latitudinal and seasonal variations. Journal of Hydrometeorology 3: 660-686.

Dailey, P.J. 2006.

Photographic Atlas Aquatic Macroinvertebrates. Piasa Watershed Creeks and Ponds. Lewis and Clark Community College 39 p.

Fernando, C.H. and S.R. Weerewardhena 2002.

Sri Lanka Freshwater Fauna and Fisheries. A Guide to the Freshwater Fauna and the Genesis of Inland Fisheries. A Third Millennium Book, Colombo. $634 \mathrm{pp}$

Hartmann, A. 2006.

Key to Odonata (Dragonflies and Damselflies) of Hindu Kush-Himalayan Region. Kathmandu University Dhulikhel, Nepal.

Houser, J.N., J.P. Mulhollandand K.O. Maloney 2006.

Upland Disturbance affects headwater stream nutrients and suspended sediments during baseflow and stormflow. Journal of Environmental Quality 35: 352-365.

Jayasuriya, A.H.M. and S.D .Abayawardana 2008.

A Study to Determine the Changes in the Biodiversity Values of Southern Sinharaja and Kanneliya Forests after the Implementation of Medium sized Project. 1st Edition. United Nations Development Programme (UNDP), Colombo, $10 \mathrm{p}$.

Leprieur, M.S.F., A.T.S. Lek-ang and T.C.S. Lek 2009.

Impact of agricultural land use on aquatic insect assemblage in Geronne rivers catchment (SW France). Aquatic Ecology 43: 999-1009.

Mandaville, S. M. 2002.

Benthic Macroinvertebrates in Freshwaters - Taxa Tolerance Values, Metrics, and Protocols. Soil and Water Conservation Society of Metro Halifax. 
Munari, C. and M. Mistri 2007.

Structure and secondary production of macrobenthic communities in an aquatic transition environment of the Gulf of olbia, Mediterranean sea. Indian Journal of Marine Science 36 (3): 216-226.

River Watch Network 1992.

Simple picture key: Major group of macroinvertibrates commonly found in freshwater New England streams. http://cdflyfishers.org/Fly\%20Tying/ aquatic\%20organisms.pdf Accessed on 2012/04/08.

Silva, A.A.D. 2009.

Water quality dynamics of low-gradient, headwater streams in a timberindustry dominated watershed in Louisiana. M.Sc. dissertation, University of North Texas, Texas.

Sivakugan, N. 2000.

Chapter 3 Soil Classification. http://eng1.jcu.edu.au/research/compgeo/ classify.pdf [Accessed on 18.05.2012]

Toriman, M.E, M.K.A. Kamarudin, M.H. Idris, N.R. Jamil, M.B. Gazim and N.A.A. Aziz 2009.

Sediment concentration and load analyses at Chini River, Pekan, Pahang Malaysia. Research Journal of Earth Sciences 1(1): 43-50.

Vannote, R.L., G.W. Minshall, K.W. Cummins, J.R. Sedell and C.E. Cushing1980. The river continuum concept. Canadian Journal of Fisheries and Aquatic Science 37: 130-137.

United States Environmental Protection Agency (USEPA) 2012. Water:monitoring and assessment. http://water.epa.gov/type/rsl/monitoring/vms51.cfm [Accessed on 05.04.2012].

Wahizatul, A.A., S.H. Long and A. Ahmad 2011.

Composition and distribution of aquatic insect communities in relation to water quality in two freshwater streams of Hulu Terengganu, Terengganu. Journal of Hazardous Materials 6(1): 148-155.

Wade, M., S. Rohm and S. Fink 2007.

Laboratory Experiment 2: Particle Size Analysis - Mechanical Method. http://student.seas.gwu.edu/ mattwade/SchoolStuff/SoilsLab/Lab2.pdf [Accessed on 14.03.2012].

Young, S.M., A. Pitawala and J. Gunatilake 2009.

Effect of agricultural practices on chemical quality of water in Kalaoya river basin. Journal of Geological Society of Sri Lanka 13: 97-104. 